\title{
A preliminary study on the distribution of spiny lobster (Panulirus spp.) in Labuan Island, Malaysia
}

\author{
Cheng-Ann Chen* and Siti Nor Fatihah \\ Borneo Marine Research Institute, Universiti Malaysia Sabah, 88400 Kota Kinabalu, Sabah, Malaysia \\ *Corresponding author: chengann@ums.edu.my
}

\begin{abstract}
There is a paucity of information on the global distribution and capture fisheries of the spiny lobster Panulirus, spp. Under the IUCN Red List produced by the International Union for Conservation of Nature that acts as a critical indicator of the health of the world's biodiversity, most of the Panulirus spp. are categorized under least concern category while some show a declining trend. Further investigations are needed due to data deficiency. The present survey was carried out in the western region of Labuan island. Seven random stations along the west coast of the Island were selected for observations during day dive. Generally, the density of the spiny lobsters was low throughout the present study. Only four individuals of two spiny lobster species were recorded. Two individuals of $P$. versicolor were observed in station 2 while the other two (P. ornatus) were spotted in station 4 . This low number could be due to the preliminary nature and limited duration of the study. Spiny lobsters tend to have a wide range of depth preferences. Two adult specimens of $P$. versicolor were spotted in an environment where turbidity was low. Further investigations over extended period of time and covering larger sampling areas will be necessary to accurately establish the habitat preferences and other ecological aspects of P. ornatus and P. versicolor.
\end{abstract}

Keywords: Spiny lobster, Panulirus spp., Depth, Turbidity, Distribution

\section{Introduction}

Tropical spiny lobsters (Panulirus spp.) are considered highvalue fisheries resources. Panulirus ornatus, Panulirus versicolor and Panulirus penicillatus are the most widely distributed species in the Philippines waters (Juinio-Menez and Gotanco, 2004) but Panulirus homarus, Panulirus timpsoni and Panulirus longipes are mostly preferred for culture in Khanh Hoa province and southern central Vietnam (Tuan and Mao, 2004). The sea cage culture of spiny lobster has been set up on the east coast of Queensland and Torres Straits in Australia. Torres Straits comprises islands in the coastal sea and provides suitable areas for the sea cage culture of spiny lobster, P. ornatus (Kenway et al., 2008). In Malaysia, limited data is available on the distribution of marine spiny lobster (Panulirus spp.). Only one species, Panulirus polyphagus, was recorded in Johor strait (Ikhwanuddin et al., 2014) and five species from Sabah waters ( $P$. ornatus, $P$. versicolor, $P$. longipes and two unidentified species) (Biusing and Chio, 2004). Besides, the main problems of spiny lobster in aquaculture industry are captive breeding and larval rearing. Challenges faced in maintaining the puerile and other developmental stages have been discussed by Fatihah et al. (2017), Fatihah et al. (2016) and Ikhwanuddin et al. (2015).

Due to high market demand, spiny lobster is targeted in capture fisheries, leading to overfishing in many regions. The fishing pressure is likely to continue increasing as landings decline in the near future. Currently, out of the total of 21 species recorded in the IUCN red list of threatened species, nine species are currently categorized as "Data Deficient" while the other thirteen species are "Least Concern" (IUCN, 2018). Out of the current nine "Data Deficient" species, two species ( $P$. argus and P. regius) have showed depletion and require more fisheries data in order to provide a more conclusive justification.

This study involved a day time dive around Labuan, off the coast of Sabah, East Malaysian state in Borneo, and was intended to collect preliminary ecological data on lobsters. It will require thorough investigations over a longer period of time to determine the habitat preferences, population density and other aspects of biology of the lobsters. This data will be helpful in their sustainable management.

\section{Materials and Methods}

The present ecological survey of the tropical spiny lobster, Panulirus spp. involved SCUBA diving and was conducted on $8^{\text {th }}$ and 14 September 2017 in Labuan, Malaysia. Labuan is located off the coast of Sabah in East Malaysia and comprises the main island and the other six smaller islands. The study area was in the western region of the main island and included seven randomly selected stations (Figure 1, Table 1). 




Figure 1. Location of the Labuan Island in Borneo together with the sampling stations.

Global Positioning System (Garmin GPS 78s) was used to detect the coordinate of each study station. The depth of the stations was recorded by depth sounder while the turbidity of the water was measured using TN-100 Turbidimeter (Eutech Instruments, United States of America). The temperature, salinity, dissolved oxygen and $\mathrm{pH}$ were determined using YSI-Multiparameter (Xylem Inc, Oklahoma, United States of America). In each station, three transact lines were set up at 10 metre distance from the dive point. The covered area was nearly $314 \mathrm{~m}^{2}$. All the data were analyzed by the help of SPSS computer software (Chicago, USA). Nonparametric kruskal wallis test was applied to compare the physico-chemical parameters of the seawater and differences, if any, in the number of specimens of Panulirus spp. between the stations were tested for significance $(p<0.05)$.

\section{Results}

The results of the non-parametric Kruskal-Wallis test identified depth of each station to be significantly different $(p=0.004)$. Most of the study stations were recorded with the depth around 4- $5 \mathrm{~m}$ except stations 3, 4 and 5. Station 3 was the deepest $(22.67 \mathrm{~m})$ followed by station $4(21.40 \mathrm{~m})$. Water temperature showed significant differences between the stations $(\mathrm{p}=0.004)$ with little fluctuations. The dissolved oxygen concentration markedly varied ( $p=0.005)$; the highest was in station 2 as compared to station 7 (Table 1). Both salinity and $\mathrm{pH}$ also showed significant differences between stations ( $p=0.003 ; 0.006$, respectively). Salinity was low in all the stations (22.91 - $24.40 \mathrm{ppt})$. Lower $\mathrm{pH}$ (7.75) was recorded in station 1 . Water transparency was high due to low turbidity, with the lowest at station 2 (0.053 NTU) which was different from other stations ( $p=0.030)$. The most turbid station in the present study was station 5 (1.15 NTU).

Low population density of the spiny lobsters (Panulirus spp.) was observed during this study. Only four individuals of two spiny lobster species were recorded (Table 2). The Pearson correlation indicated that the occurrence of $P$. ornatus was positively correlated with the depth $(r=0.446 ; p=0.043)$, indicating the depth preference of the species in nature (Figure 2). Besides, P. versicolor was negatively affected by the turbidity $(r=-0.523 ; \mathrm{p}=0.022)$ due to its preference for clearer water (Figure 3).

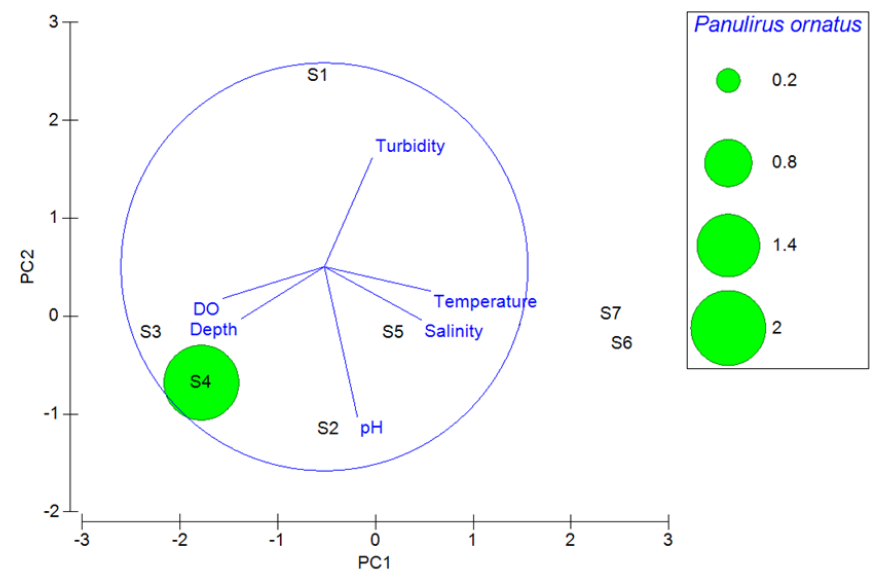

Figure 2. Principal Component Analysis of the in situ environmental parameters at all the sampling stations in Labuan coastal waters.

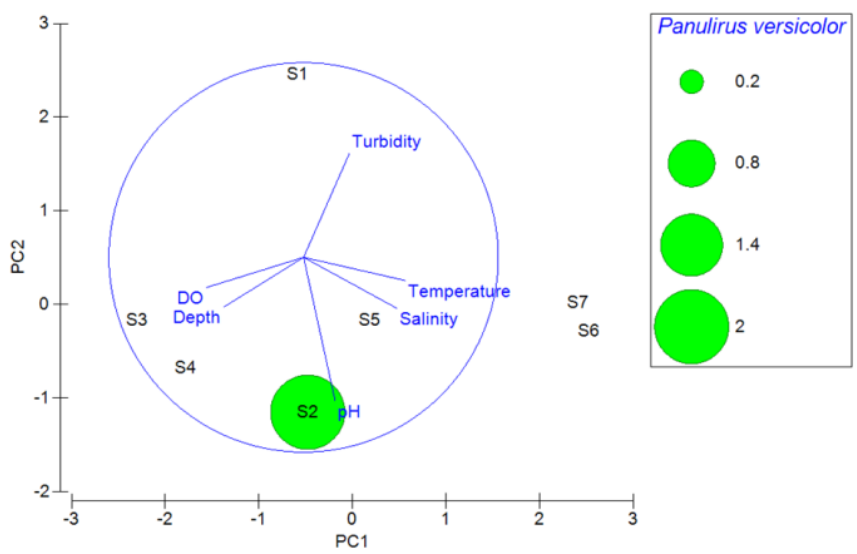

Figure 3. Principal Component Analysis of the in situ environmental parameters at the sampling stations in Labuan coastal waters.

\section{Discussion}

Low number of the Panulirus spp. was probably due to day dive sampling. All the species of genus Panulirus are mainly nocturnal and live in coral or rocky reefs in depths less than $40 \mathrm{~m}$ (Chan, 1998). The adults are usually active at night and use sand areas for foraging (Senevirathna et al., 2017). Frisch (2007) conducted a short-term (10 days) study of the movement of $P$. versicolor and concluded that the male moves over a greater distance than the female (36 $\mathrm{m}$ vs. 18 $\mathrm{m})$. The farthest distance reported is $459 \mathrm{~m}$, and that reflects the level of this activity of the Panulirus spp. during night time. Both the P.ornatus were observed in the artificial shelters (unused truck tyre) during the day dive (Figure 4). The present results supported the findings of Priyambodo et al. (2015) that P. ornatus does not prefer hard substrates. Booth (2001) noted that most of the Palinuridae preferred small holes and crevices in hard substrates. However, the hard substrates that are easily covered by barnacles are expected to decrease the colonization of the P. ornatus. 
Table 1. Geographical coordinates and in situ physico- chemical water parameters of each study station.

\begin{tabular}{|c|c|c|c|c|c|c|c|}
\hline Station & $\begin{array}{l}\text { Geographical } \\
\text { coordinates }\end{array}$ & Depth (m) & $\begin{array}{c}\text { Temperature } \\
\left({ }^{\circ} \mathrm{C}\right) \\
\end{array}$ & $\begin{array}{c}\text { Dissolved oxygen } \\
(\mathrm{mg} / \mathrm{L})\end{array}$ & $\begin{array}{l}\text { Salinity } \\
\text { (ppt) }\end{array}$ & $\mathrm{pH}$ & $\begin{array}{l}\text { Turbidity } \\
\text { (NTU) }\end{array}$ \\
\hline 1 & $\begin{array}{l}\text { N0520'12.1" } \\
\text { E11511'06.1" }\end{array}$ & $4.97 \pm 0.32$ & $30.37 \pm 0.058$ & $3.73 \pm 0.058$ & $23.28 \pm 0.00$ & $7.75 \pm 0.17$ & $1.12 \pm 0.19$ \\
\hline 2 & $\begin{array}{l}\mathrm{N}^{\circ} 5^{\circ} 20^{\prime} 43.0^{\prime \prime} \\
\mathrm{E} 115^{\circ} 11^{\prime} 01.9^{\prime \prime}\end{array}$ & $5.80 \pm 0.00$ & $30.60 \pm 0.00$ & $4.23 \pm 0.23$ & $24.11 \pm 0.058$ & $8.10 \pm 0.048$ & $0.053 \pm 0.038$ \\
\hline 3 & $\begin{array}{l}\text { N } 05^{\circ} 22^{\prime} 56.0^{\prime \prime} \\
\text { E } 115^{\circ} 10^{\prime} 15.5^{\prime \prime}\end{array}$ & $22.67 \pm 0.058$ & $30.13 \pm 0.058$ & $4.27 \pm 0.11$ & $22.91 \pm 0.058$ & $8.12 \pm 0.090$ & $0.61 \pm 0.21$ \\
\hline 4 & $\begin{array}{l}\text { N } 05^{\circ} 18^{\prime} 51.3^{\prime \prime} \\
\text { E } 115^{\circ} 09^{\prime} 27.0^{\prime \prime}\end{array}$ & $21.40 \pm 0.20$ & $30.23 \pm 0.12$ & $4.04 \pm 0.055$ & $23.20 \pm 0.012$ & $8.16 \pm 0.026$ & $0.44 \pm 0.25$ \\
\hline 5 & $\begin{array}{l}\text { N } 05^{\circ} 17^{\prime} 10.0^{\prime \prime} \\
\text { E } 115^{\circ} 09^{\prime} 22.3^{\prime \prime}\end{array}$ & $13.83 \pm 1.05$ & $30.77 \pm 0.058$ & $3.67 \pm 0.058$ & $23.72 \pm 0.015$ & $8.20 \pm 0.058$ & $1.15 \pm 0.31$ \\
\hline 6 & $\begin{array}{l}\text { N } 05^{\circ} 20^{\prime} 21.3^{\prime \prime} \\
\text { E } 115^{\circ} 11^{\prime} 17.9^{\prime \prime}\end{array}$ & $4.37 \pm 0.31$ & $31.63 \pm 0.058$ & $3.00 \pm 0.10$ & $24.40 \pm 0.058$ & $8.19 \pm 0.058$ & $0.75 \pm 0.29$ \\
\hline 7 & $\begin{array}{l}\text { N } 05^{\circ} 20^{\prime} 13.3^{\prime \prime} \\
\text { E } 115^{\circ} 11^{\prime} 05.6^{\prime \prime}\end{array}$ & $4.53 \pm 0.058$ & $31.43 \pm 0.058$ & $2.97 \pm 0.058$ & $24.29 \pm 0.058$ & $8.21 \pm 0.058$ & $0.90 \pm 0.20$ \\
\hline
\end{tabular}

Table 2. Distribution of Panulirus spp. in each study station: Presence $(+)$ or absence $(-)$.

\begin{tabular}{ccc}
\hline Station & P. ornatus & P. versicolor \\
\hline 1 & - & - \\
2 & - & + \\
3 & - & - \\
4 & + & - \\
5 & - & - \\
6 & - & - \\
7 & - & - \\
\hline
\end{tabular}

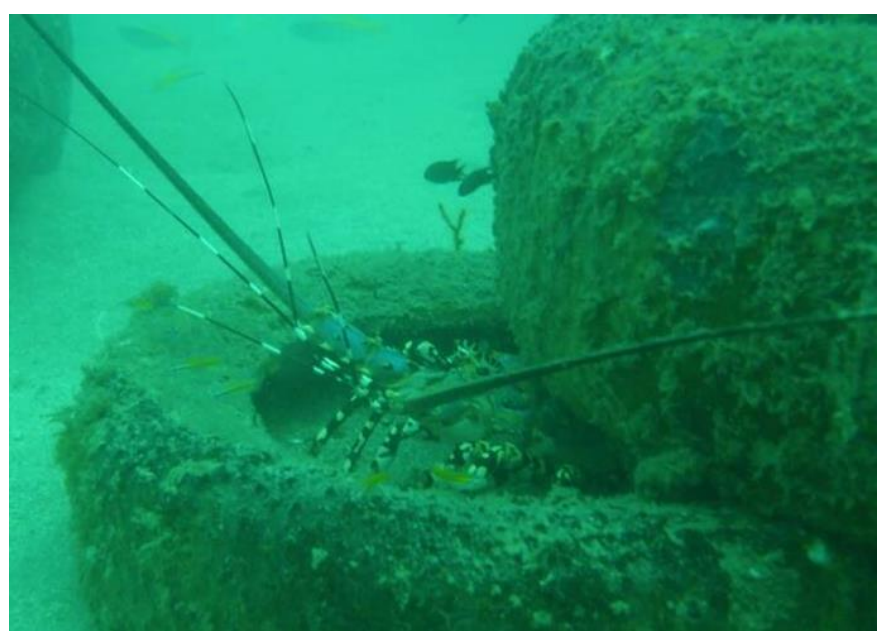

Figure 4. Panulirus ornatus in the artificial shelter recorded in station 4

\section{Conclusion}

The results of the present preliminary daytime survey indicated only two species of Panulirus spp. represented by two individuals of each in Labuan coastal waters. Depth and turbidity appear to influence the distribution of Panulirus spp. in the area in addition to the presence of sheltered environment for protection. However, due to small sample size during the preliminary survey it is not possible to generalize the pattern of distribution or habitat preferences of Panulirus spp. This topic deserves importance for management of lobsters in Malaysian waters.

\section{Acknowledgements}

This research was funded by Universiti Malaysia Sabah under SLB0123-STWN-2016 and SLB0126-SG-2016. We appreciate the facilities provided by Borneo Marine Research Institute, Universiti Malaysia Sabah, Our special thanks are due to Miss Nuratiqah Isninul and Miss Dg Nur Suliza Binti Sufian for their help throughout the sampling.

\section{References}

Biusing, R. \& Chio F.L. (2014). Status of Spiny Lobster Resources in Sabah, Malaysia. Ed: Williams, K.C., In: Spiny Lobster Ecology and Exploitation in the South China Sea Region: Proceedings of a workshop held at the Institute of Oceanography, Nha Trang, Vietnam. July 2014. pp 712.

Booth, J. D. (2001). Habitat preferences and behaviour of newly settled Jasus edwardsii (Palinuridae). Marine and Freshwater Research. 52, 1055-1065. Http://dx.doi.org/10.1016/j.aquaculture.2015.02.037

Chan, T. Y. (1998). Lobster. In: Carpenter KE, Niem VH (eds.) FAO Species identification guide for fishery purposes. The living marine resources of the Western Central Pacific. Volume 2. Cephalopods, Crustaceans, Holothurians and Sharks. FAO, Rome.

Dao, H. T., Smith-Keune, C., Wolanski, E., Jones, C. M. \& Jerry, D. R. (2015). Oceanographic currents and local ecological knowledge indicate, and genetics does not refute, a contemporary pattern of larval dispersal for the ornate spiny lobster, Panulirus ornatus in the south-east Asian archipelago. PLoS ONE, 10(5), 1-19. https://doi.org/ 10.1371/journal.pone.0124568

Fatihah, S. N., Muhd-Farouk, H. Amin-Safwan, A., Mahsol, K. H. \& Ikhwanuddin, M. (2017). Histological characteristisc on the testes of mud spiny lobster, Panulirus polyphagus (Herbst, 1793). Pakistan Journal of Biological Sciences 20 (7): 365-371. DOI: 10.3923/pjbs.2017.365.371

Fatihah, S. N., Jasmani, S., Abol-Munafi, A. B., Noorbaiduri, S., MuhdFarouk, H. \& Ikhwanuddin, M. (2016). Development of a sperm cryopreservation protocol for the mud spiny lobster, Panulirus polyphagus. Aquaculture 462: 56-63. https://doi.org/10.1016/j.aquaculture. 2016.04.025

Frisch, A. J. (2007). Short- and long-term movements of painted lobster (Panulirus versicolor) on a coral reef at Northwest Island, Australia. Coral Reefs 26(2), 311-317. https://doi.org/10.1007/s00338-006-0194-6

Holthuis, L. B. (1991). Marine lobsters of the world. An annotated and illustrated catalogue of species of interest to fisheries known to date. FAO species catalogue. Vol. 13. FAO Fish Synop 125. 1-292. 
Ikhwanuddin, M., Fatihah, S. N., Nurul, J. R., \& Zakaria, M. Z. (2014). Biological Features of Mud Spiny Lobster, Panulirus polyphagus ( Herbst, 1793 ) from Johor Coastal Water of Malaysia. World Applied Sciences Journal 31(12), 2079-2086. https://doi.org/10.5829/idosi.wasj. 2014.31.12.69

Ikhwanuddin, M., Fatihah, S. N., Nurfaseha, A. H., Ruhinisa, R., Tira, Z. Z., Shamsudin, A., Siti Aishah, A. \& Abol-Munafi, A. B. (2015). Effect of water salinity on ovarian maturation stages and embryonic development of mud spiny lobster, Panulirus polyphagus. Journal of Fisheries and Aquatic Science 10: 244-254. DOI: 10.3923/jfas.2015.244.254

IUCN, (2018). The IUCN List of Threatened Species. Website: http://www.iucnredlist.org. Accessed date: 1 June 2018.

Juinio-Menez, M. A. \& Gotanco, R. R. (2004). Status of spiny lobster resources of the Philippines. In: K. C. Williams (Ed.), Proceedings of a Workshop on Spiny Lobster Ecology and Exploitation in the South China Sea Region. ACIAR Proceedings No. 120, Australian Centre for International Agricultural Research, Canberra, pp. 3-6.

Kenway, M., Salmon, M., Smith, G. \& Hall, M. (2008). Potential of seacage culure of Panulirus ornatus in Australia. Proceeding of an International Symposium (pp 18-25). Nha Trang, Vietnam: Australian Centre for International Agricultural Research (ACIAR).

Milton, D. A., Satria, F., Proctor, C. H., Prasetyo, A. P., Utama, A. A. \& Fauzi, M. (2014). Environmental factors influencing the recruitment and catch of tropical Panulirus lobsters in southern Java, Indonesia. Continental Shelf Research 91, 247-255. https://doi.org/10.1016/j.csr.2014.09.011

Priyambodo, B., Jones, C. \& Sammut, J. (2015). The effect of trap type and water depth on puerulus settlement in the spiny lobster aquaculture industry in Indonesia. Aquaculture 442: 132-137. https://doi.org/10.1016/j.aquaculture.2015.02.037

Senevirathna, J. D. M., Kodikara, G. R. L., \& Munasinghe, D. H. N. (2017). Analysis of habitat characteristics of the scalloped spiny lobster, Panulirus homarus (Linnaeus, 1758) in their home range along the southern coast of Sri Lanka. Indian Journal of Fisheries 64(1), 1-8. https://doi.org/10.21077/ijf.2017.64.1.47483-01

Tuan, L. A. \& Mao, N. D. (2004). Present status of lobster cage culture in Vietnam. Proceeding of the ACIAR lobster ecology workshop, pp 24-30. Institute of Oceanography, Nha Trang, Vietnam.

Wahyudin, R.A.,Wardiatno, Y., Boer, M., Farajallah, A. \& Hakim, A.A. (2017). Short Communication: A new distribution record of the mud-spiny lobster, Panulirus polyphagus (Herbst, 1793) (Crustacea, Achelata, Palinuridae) in Mayalibit Bay, West Papua, Indonesia. Biodiversitas 18: 780-783. DOI: $10.13057 /$ biodiv/d180248 